\title{
Mixed-Mating Strategies and their Sensitivity to Abiotic Variation in Viola Lanceolata L. (Violaceae)
}

\author{
Victoria A. Ranua ${ }^{1}$ and Cynthia Weinig ${ }^{*}, 2$ \\ ${ }^{I}$ Department of Plant Biology, University of Minnesota, 210 Biological Sciences Center, 1445 Gortner Ave S., Saint \\ Paul, Minnesota, 55372, USA \\ ${ }^{2}$ Departments of Botany and Molecular Biology, University of Wyoming, 1000 E. University Ave. Laramie, WY 82070 , \\ USA
}

\begin{abstract}
Mating-system expression is sensitive to environmental conditions, and can be an important determinant of lifetime fitness because progeny that are produced via outcrossing vs. selfing may differ in quality. We quantified sexual and asexual reproduction in Viola lanceolata, a regionally threatened species, across populations that varied in disturbance history and across microsites that differed in percent soil moisture, irradiance, and temperature. In V. lanceolata, reproduction can occur sexually through facultatively outcrossing chasmogamous $(\mathrm{CH})$ flowers and obligately selfing cleistogamous (CL) flowers in addition to asexually via stolons. The frequency of individuals producing $\mathrm{CH}$ and $\mathrm{CL}$ flowers differed among sites as did the frequency of vegetative reproduction. Interestingly, sites also differed in fruit maturation success, with $\sim 33,100$, and $16 \%$ of the $\mathrm{CH}$ fruits matured in the oldest, intermediate, and most-recently disturbed populations respectively. Analogous site differences in CL fruit maturation were observed. Cleistagamous, but not $\mathrm{CH}$, reproduction was also dependent on percent soil moisture. The observed differences in fruit maturation success likely lead to variable rates of outcrossed $v s$. self-fertilized seed production; as a consequence, populations are likely to differ in genetic structure and in relative dependence on chasmogamy vs. cleiostogamy for population growth. Finally, CL flower and stolon production were negatively correlated, suggesting a tradeoff between sexual and asexual reproduction that might affect population growth.
\end{abstract}

Keywords: Chasmogamy, cleistogamy, mixed-mating system, trade-offs, Viola lanceolata.

\section{INTRODUCTION}

Many plant species exhibit mixed-mating strategies (Darwin 1877, Lord 1981, Schemske and Lande 1985, Goodwillie et al. 2005), whereby progeny are produced by both outcrossing and self-fertilization. Mixed mating may occur via distinct floral types, where plants produce 'open' (chasmogamous or $\mathrm{CH}$ ) flowers that permit outcrossing or 'closed' (cleiostogamous or CL) flowers that are obligately self-fertilizing. The relative frequency with which floral types are produced, and hence mating-system expression, may vary as a consequence of local environmental conditions. In Impatiens capensis, the production of metabolically costly $\mathrm{CH}$ flowers increases as density and herbivory rates decrease (Schmitt et al. 1987, Steets et al. 2004). In other species, $\mathrm{CH}$ flower production has been shown to increase as light availability increases (Mattila and Salonen 1995, Jensen and Meyer 2001, Cortés-Palomec and Ballard 2006) and as litter abundance decreases (Jensen and Meyer 2001). Mating system expression is evolutionarily relevant, because the relative quality of progeny produced by outcrossing vs. selfing can vary greatly (Charlesworth and Charlesworth 1987).

*Address correspondence to this author at the Departments of Botany and Molecular Biology, University of Wyoming, 1000 E. University Ave., Laramie, WY 82070, USA; Tel: 307-766-6378; Fax: 307-766-2851; E-mail: cweinig@uwyo.edu

Handling Editor: Pierre-Olivier Cheptou
Moreover, because the general trend is for selfing to increase as environmental quality decreases (Schemske 1978, Waller 1979, Cortés-Palomec and Ballard 2006), systematic decreases in environmental quality could lead to population genetic changes such as decreases in heterozygosity and increases in population substructure (Falconer and Mackay 1997). Given the potential fitness effects and population genetic consequences, understanding mating-system expression is likely important to understanding population dynamics of many species and to management of rare species in particular. Yet, few if any studies have examined whether mating system expression of rare species varies with environment.

Mating system expression may vary not only with environmental conditions, but also with internal resource status. Generally, the production of both $\mathrm{CH}$ and $\mathrm{CL}$ floral types increases with plant size (Solbrig 1981, Solbrig et al. 1988), and a positive correlation is observed between reproductive modes. This effect of vigor on trait correlations is wellknown in the life-history literature, i.e., large vigorous individuals have more resources and/or meristems to allocate to multiple functions simultaneously than small individuals can allocate to any single function, resulting in positive associations between life-history traits even when tradeoffs are predicted (Watson 1984, Geber 1990, Stearns 1992). Although the association between $\mathrm{CH}$ and $\mathrm{CL}$ flower production is often positive, it is worth noting that many plant species reproduce not only sexually via flower production 
but also asexually through stolons (that is, shoots that grow horizontally along the soil surface and produce roots and new shoots at nodes). As with $\mathrm{CH}$ vs. CL flower production, tradeoffs between sexual $v s$. asexual reproduction could arise from either resource limitation or meristem limitation, if inflorescences and stolons derive from a common pool of meristems. The potential for tradeoffs between sexual vs. asexual reproduction remains largely uninvestigated, despite the high frequency with which plant species may colonize new microsites via stolons (Schnellner et al. 1982, Hutchison and Bradley 1986, Huber et al. 1999, Marcussen 2003). Tradeoffs between sexual and asexual reproduction may also be important where both sexual seed production and asexual reproduction are critical to population maintenance or reestablishment following a disturbance event (Milburn and Husveth 2004).

Because selfed $v s$. outcrossed progeny may differ in quality, it is important to quantify fitness at all life-history stages (i.e., germination rates, survival to maturity, and fecundity) for both progeny types in order to understand population dynamics under mixed mating. In a recent study, Steets et al. (2007) examined fitness across diverse lifehistory stages in the cosmopolitan temperate annual plant, Impatiens capensis, which produces both $\mathrm{CH}$ and $\mathrm{CL}$ flowers. Selfed progeny produced by CL flowers had higher germination rates than did outcross progeny from $\mathrm{CH}$ flowers in I. capensis, while outcross progeny exhibited a fecundity advantage relative to individuals produced by selfing. Over all life-history stages, population growth in this species was more sensitive to the performance of progeny resulting from selfing, indicating the demographic importance of cleistogamous reproduction (Steets et al. 2007). In another species, the neotropical herb, Calathea micans, progeny that result from outcrossing are most important to population growth (LeCorff and Horvitz 2005). In rare species, seed collection from natural populations is often prohibited, limiting the opportunity to examine the fitness consequences of all life-history stages. However, even in protected species, it is possible to quantify the frequency with which chasmogamous $v s$. cleistogamous flowers are produced as well as the success with which the different fruits mature. These are important first steps in determining the relative contribution of different reproductive modes to population growth.

Here, we examine reproductive effort in Viola lanceolata L., a threatened species in Minnesota (MN Department of Natural Resources 2007). Persistence of populations of this perennial wetland species is disturbance-dependent (Keddy and Reznicek 1982, Solbrig et al. 1988, Wisheu and Keddy 1991, Milburn and Husveth 2004, Owen-Koning 2005), and the species reproduces sexually via the production of $\mathrm{CH}$ and CL flowers and asexually via stolons (Russell 1958, Mohlenbrock 1978, Milburn and Husveth 2004). The natural history of this species offers the opportunity to examine both how environment (site disturbance and microsite variation in abiotic factors) affects mating-system expression and if tradeoffs exist between reproductive modes (chasmogamy $v s$. cleistogamy or sexual vs. asexual). We studied several populations of $V$. lanceolata that vary in disturbance history. Some populations occur within active native habitat restoration projects (Milburn and Husveth 2004), while another is undergoing natural succession. Our specific goals were to determine (1) if populations differ in the frequency of $\mathrm{CH}$ vs. CL flower production, or in the success with which $\mathrm{CH}$ and/or CL flowers are converted to fruits, (2) if differences in reproductive output among populations are a result of differences in the frequency of reproductive individuals and/or the mean number of flowers produced by reproductive individuals, (3) how plant size and local abiotic factors are related to reproductive effort, and (4) if allocation tradeoffs exist between chasmogamy vs. cleistogamy and/or between sexual $v s$. asexual reproduction.

\section{METHODS}

\section{Species Description}

Viola lanceolata, is a member of the Stolonasae subsection of the Violaceae (Russell 1955). The species' range extends west to Minnesota, where it is rare. It widely occurs in most states to the south and east. Suitable sandy wetland habitat in Minnesota is a naturally limiting factor for this species. Since Euro-American settlement of Minnesota in the 1850's, the number of suitable sites has been further reduced by wetland drainage, wildfire suppression, local extirpation of large grazing animals, and local prevalence of non-native invasive species, such as Phalaris arundinacea L., Phragmites australis Trin. ex. Streud., and Rhamnus frangula L. These changes have also led to population extirpation (Milburn and Husveth 2004).

Flowering typically begins between May and June with $\mathrm{CH}$ flowers produced early in the season (Swink 1952, Russell 1960), and there is never more than one $\mathrm{CH}$ flower open at a time on an individual (V. Ranua, personal observation). The switch between $\mathrm{CH}$ and $\mathrm{CL}$ flower production is abrupt, and CL flowers appear July through October. While the showy $\mathrm{CH}$ flowers stand erect above the ground, the diminished CL flowers are at the soil surface or just above on erect peduncles (Mohlenbrock 1978). During fruit ripening, the infructescences developing from both floral types are propelled upright and are visibly indistinguishable. The ripened fruit dehisces, resulting in the expulsion of the seeds into the air. However, it is not uncommon that some seeds remain in the pod after dehiscence (V. Ranua, personal observation).

The rate of individual seed production decreases as succession proceeds, presumably as a consequence of increased interspecific competition for resources (Solbrig et al. 1988). However, viable seeds within the seed bank quickly germinate following a disturbance event (Keddy and Reznicek 1982, Wisheu and Keddy 1991), including grazing, fire, or inundation followed by drawdown. In some sites in Minnesota, hundreds of seedlings may germinate following disturbance (V. Ranua, personal observation).

Some species within the genus Viola have mechanisms that permit delayed selfing within $\mathrm{CH}$ flowers. Specifically, in $V$. pubescens, the stigma bends and makes contact with dehisced anthers in older flowers. However, this mechanism is not widespread within the genus, and there is no evidence for it in $V$. lanceolata or its close relatives (Beattie 1969, Beattie and Culver 1979, Banasinska and Kuta 1996). Moreover, even in species with this active mechanism, the frequency of selfed seeds within $\mathrm{CH}$ flowers can be low 


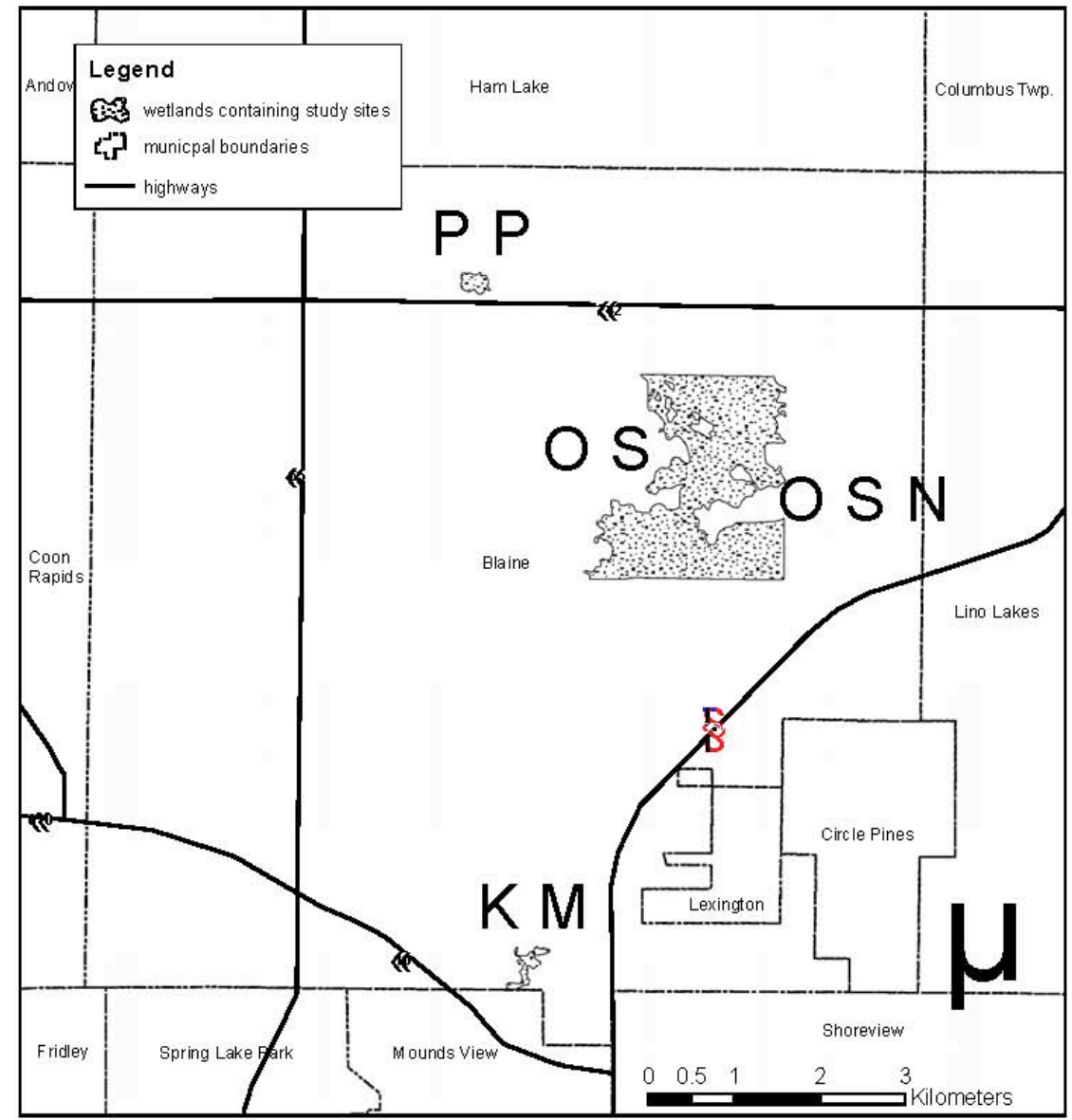

Fig. (1). Land cover types for each of 4 study populations of Viola lanceolata. OS and OSN occur in the same cover type.

Table 1. Summary of Disturbance History, Disturbance Type, Population Size, and Site Conditions for Experimental Populations of Viola lanceolata

\begin{tabular}{|c|c|c|c|c|}
\hline Population & Recent Disturbance Events & Disturbance Type & Population Size & Land Use \\
\hline \hline Kane Meadows (KM) & None in 15 yrs & None & $\sim 50$ & City open space \\
\hline Pioneer Park (PP) & $1989,2003,2005,2006$ & $\begin{array}{c}\text { Soil excavation, tree and shrub removal, } \\
\text { fall prescribed fires }\end{array}$ & $>1,000$ & City park \\
\hline Open Space (OS) & 2007 & Weed whipping, raking & $>1,000$ & City open space \\
\hline Open Space New (OSN) & 2007 & Vegetation removal, deep soil scraping & $<100$ & City open space \\
\hline
\end{tabular}

\begin{tabular}{|c|c|c|}
\hline Population & $\begin{array}{c}\text { Early Season } \\
\text { Soil Moisture }{ }^{\mathbf{1}} \text { Irradiance }\end{array}$ & $\begin{array}{c}\text { Mid-Season } \\
\text { Temperature }\end{array}$ \\
\hline \hline Kane Meadows (KM) & $34.8 \pm 2.7 \mathrm{~A}, 1068 \pm 52 \mathrm{~A}, 16.7 \pm 0.2 \mathrm{~A}$ & $8.5 \pm 1.1 \mathrm{~A}, 627 \pm 61.9 \mathrm{~A}, 26.8 \pm 0.3 \mathrm{~A}$ \\
\hline Pioneer Park (PP) & $52.2 \pm 3.8 \mathrm{~B}, 1494 \pm 73 \mathrm{~B}, 14.4 \pm 0.2 \mathrm{~B}$ & $40.4 \pm 1.5 \mathrm{~B}, 1242 \pm 85.7 \mathrm{~B}, 27.7 \pm 0.5 \mathrm{~B}$ \\
\hline Open Space (OS) & $41.6 \pm 2.6 \mathrm{C}, 1817 \pm 49 \mathrm{C}, 16.4 \pm 0.2 \mathrm{~A}$ & $20.2 \pm 1.1 \mathrm{C}, 1612 \pm 59.3 \mathrm{C}, 26.3 \pm 0.3 \mathrm{~A}$ \\
\hline Open Space New (OSN) & NA & NA \\
\hline
\end{tabular}

${ }^{1}$. Soil moisture values are percents, ${ }^{2}$. Irradiance units are $\mu \mathrm{mols} \mathrm{m}^{-2} \mathrm{sec}^{-1},{ }^{3}$. Temperatures are in ${ }^{\circ} \mathrm{C}$. Letters denote significant pairwise differences between populations as determined from Tukey's post-hoc test.

(e.g., 0.07) (Culley 2002). We therefore expect that the majority of seeds within $\mathrm{CH}$ fruits are the product of outcrossing. The species also reproduces asexually through the production of vegetative stolons, with connections that can last for several years (Newell 1982). Existing $V$. lanceolata plants readily colonize disturbed microsites by means of stolon production (V. Ranua, personal observation).

\section{Study Area}

We chose four populations (Kane Meadows (KM), Pioneer Park (PP), Open Space (OS), and Open Space New (OSN) in the City of Blaine, Anoka County, MN (Fig. 1) for investigation based on varying history of disturbance (Table 1). The sites ranged in disturbance history from none recorded in recent history (in the last $15 \mathrm{yrs}$ ) to recent soil 
disturbance as part of restoration activity (in the last several months of 2007); populations ranged in size from 10's to 1,000's of plants (Table 1). All populations occurred in wet meadows or rich fens and were located on public lands in the City of Blaine. The population sites occur within the Anoka Sandplain, where large blocks of glacier ice were covered by sand and the sandy wetlands were formed as the glaciers melted (Wovcha et al. 1995). Soils are very poorly drained organic materials over sandy glacial outwash, ranging from Markey muck at KM to Rifle mucky peat at the other three sites (USDA Natural Resource Conservation Service 2006).

\section{Reproductive Effort, Biotic and Abiotic Factors}

In early spring 2007, we inconspicuously marked 50 individual plants each at KM, OS, and PP with a wooden marker to examine reproductive characteristics, as well as the influence of biotic and abiotic factors on reproduction. When seedlings appeared at OSN in midsummer 2007 after disturbance, we marked 27 seedlings. At all locations, plants were chosen at random by running transects across the population and including for study those plants closest to a set interval, e.g., every $20 \mathrm{~cm}$ along the transect. We conducted a census of each marked plant every 6-8 days during the 2007 growing season.

To monitor CH and CL flower and fruit development, we marked each reproductive meristem as it developed with colored bands and then tracked the development of individual buds through time (Schemske 1978). At each census, we classified reproductive parts as (1) new CH or CL flower, (2) developing fruit, (3) aborted fruit, or (4) dehisced fruit. Within the study area, $\mathrm{CH}$ flower production began the $1^{\text {st }}$ wk of May and ended by the $1^{\text {st }}$ wk of June, while CL flower production began in the $1^{\text {st }}$ wk of June and continued until late September. For both floral types, fruit production was complete 6-8 wks after the production of new flowers ended. Number of fruits was used an estimate of reproductive effort, because fruits could not be collected for seed counts due to the species' threatened status. At the onset of flowering (May) and at mid-season (July), we recorded the length of the longest leaf and the total number of leaves. These two sets of leaf traits are referred to as 'early' and 'mid' season, respectively. In July, stolon production became apparent, and all plants were scored for the presence of at least one stolon. Determining exact stolon number, while desirable, would have entailed more disturbance of surrounding soil and vegetation.

We measured abiotic environmental conditions at monthly censuses from May through August. Soil temperature was measured with an Accurite probe (Accurite, Lake Genova, Wisconsin) at each plant at a depth of $5 \mathrm{~cm}$. The percent soil moisture was measured using an ECH2O soil moisture probe (Decagon Devices, Pullman, Washington) at each plant at the depth of $5 \mathrm{~cm}$. Light quantity was measured using a LI-COR LI-250 light meter (LI-COR, Lincoln, Nebraska) at each plant. Light quantity was recorded at the rosette on days when total cloud cover was estimated at less than $30 \%$, and no clouds covered the sun at the time of measurement.

Early season vandalism to our plant markers reduced the PP study population to 31 . Vandals removed most plant markers at OS and OSN in September 2007, forcing a premature end to the study. Because the natural end of $\mathrm{CL}$ flowering is October, this study likely underestimates total CL fruit production by one to four fruits (V. Ranua, personal observation).

\section{Statistical Analysis}

To evaluate variation in abiotic conditions, we used oneway ANOVA to test for population differences in early as well as mid-season soil moisture levels, irradiance, and soil temperatures. Significant pairwise differences between sites in the abiotic factors were determined using Tukey's posthoc test (Sokal and Rohlf 1995).

With regard to reproductive characters, total production of $\mathrm{CH}$ flowers was calculated as the sum of flowers produced over the first four censuses, i.e., over all censuses in which new $\mathrm{CH}$ flowers were produced. We calculated two estimates of CL flower production, in part to control for vandalism late in the season. For an estimate of early reproductive effort, we summed CL flowers produced during censuses 3 (when CL flower production began) through census 9 (a mid-season census that was conducted prior to vandalism). For total CL flower production, we took the sum of CL flowers produced over all censuses performed during the growing season. The early CL estimate allows direct comparison with the $\mathrm{CH}$ flower production and, for instance, a test of whether early allocation to chasmogamous $v s$. cleistogamous reproduction is correlated. We summed the number of $\mathrm{CH}$ fruits and total number of $\mathrm{CL}$ fruits over all censuses to determine total reproduction through $\mathrm{CH}$ and $\mathrm{CL}$ reproduction, with the caveat the total $\mathrm{CL}$ reproduction is slightly underestimated.

One-way analysis of variance (ANOVA) was used to test for significant differences among populations in leaf size, leaf number, and both $\mathrm{CH}$ and $\mathrm{CL}$ flower and fruit production (PROC GLM, SAS 2004). Individuals that failed to reproduce were included in these analyses, and received a score of 0 for flower or fruit number. Due to the large number of non-reproductive individuals per population, the distribution of some reproductive traits was non-normal; a non-parametric rank test was therefore performed for flower and fruit traits (PROC RANK, SAS 2004). However, ANOVA is typically robust to the assumption of normality at moderate sample sizes (Rutherford, 2001), and significance tests from the non-parametric analyses did not differ from the ANOVA results. Only results of the ANOVA are presented in order that similar statistical tests are applied to all traits. Due to the large number of measured traits, we performed a sequential Bonferroni correction for multiple tests (Rice 1989). Tukey's post-hoc test was used to determine significant pairwise differences between populations.

Chi-square tests were used to test for population differences in the frequency of individuals reproducing sexually, via $\mathrm{CH}$ or $\mathrm{CL}$ flower and fruit production (PROC FREQ, SAS 2004). In particular, a high level of flower production (or fruit production) could arise from either of 2 demographic patterns: from the presence of a large number of reproductive individuals that each has a low-moderate number of flowers, or from a small number of reproductive 
individuals that each has high flower production. The relative frequency of reproductive individuals as well as their average fecundity is of interest, because population demography could influence the minimum viable population size. Chi-square tests were also used to test for significant population differences in the frequency of individuals reproducing asexually, via stolons.

The association between allocation to $\mathrm{CH}$ vs. CL was tested using a regression of $\mathrm{CL}$ flowers on $\mathrm{CH}$ flowers (PROC GLM, SAS 2004), under the hypothesis that high early allocation to chasmogamy might reduce resources/ meristems available for production of cleistogamous flowers. The relationship between sexual and asexual reproduction was explored using logistic regression within the one site (OS) where similar numbers of individuals did and did not produce stolons, i.e., within-level replication was high. In this analysis, the binary trait of stolon presence $v s$. absence was regressed on the sexual traits (total $\mathrm{CH}$ flower and $\mathrm{CL}$ flowers) (PROC LOGISTIC, SAS 2004). Sexual and asexual reproductive effort might be positively correlated if large individuals produce both flowers and stolons, or negatively correlated if resource and/or meristem tradeoffs exist.

We were also interested in determining if any abiotic factors might account for significant differences among populations in the relative output of $\mathrm{CH}$ vs. CL fruit (i.e., environmental sources of variation in mating system expression) or in total reproductive output (i.e., the quality of these sites for $V$. lanceolata). Analysis of covariance was used to evaluate the main effects of population, plant size (estimated from length of the longest leaf), soil moisture, irradiance, and soil temperature as well as the two-way interactions of population $\times$ moisture, population $\times$ irradiance, population $\times$ temperature, moisture $\times$ irradiance, moisture $\times$ temperature, and irradiance $\times$ temperature on reproductive traits. Temperature was ultimately dropped from the model as preliminary analyses failed to reveal significant main effects or interaction effects with this environmental factor ( $p>0.20$ for all temperature effects). We performed a sequential Bonferroni correction using the significance level of the overall model to correct for the multiple tests performed on the 5 reproductive traits.

Data for OSN is limited to the frequency of CL reproductive individuals, presence $v s$. absence of stolons, and leaf number, because the first appearance of seedlings occurred in midsummer. While most statistical analyses did not include this population, this information is included because it is relevant to the life-history of $V$. lanceolata and is not available elsewhere.

\section{RESULTS}

We used ANOVA to test for population differences in abiotic factors that might affect mating system expression. Populations differed significantly in all measured abiotic factors both early- and mid-season (Table 1). At both the early- and mid-season censuses, KM was the driest population, followed by OS, and PP. KM experienced the lowest irradiance of any population, while PP was intermediate, and OS had the highest irradiance.
As a consequence of differences in disturbance history and abiotic factors, we expected that populations might differ in average individual size (as estimated from leaf traits) and mating system expression. ANOVA indicate that populations differed significantly in average plant size and both $\mathrm{CH}$ and $\mathrm{CL}$ flower production (Table 2), and results of all individual ANOVA remain significant following a sequential Bonferroni correction for multiple tests. Plants from the older populations (KM, PP, and OS from oldest to youngest, respectively) had both a greater number of leaves and larger average leaf size at early-season censuses (Fig. 2A). At the mid-season census, plants at the newly disturbed population (OSN) that consisted entirely of new germinants had the largest number of but also smallest leaves. Plants at $\mathrm{KM}$ and PP produced slightly more than $1 \mathrm{CH}$ flower on average, which is significantly more than the number produced by individuals at OS. Early-season CL flower production (calculated as the total number of flowers produced in censuses $3-9$ ) also differed among populations (Table 2), with individuals at KM producing significantly more flowers on average than individuals at either PP or OS (Fig. 2B). Total CL flower production differed significantly among the populations (Table 2), with plants at the oldest populations, KM and PP, producing more CL flowers than the youngest populations, OS and OSN (Fig. 2B).

Table 2. One-Way Analysis of Variance Testing the Effect of Population on Reproductive and Vegetative Traits. Model $r^{2}$ range from 0.07-0.19

\begin{tabular}{|c|c|c|c|c|}
\hline Trait & df & Mean squares & F-value & Pr $>\mathbf{F}$ \\
\hline \hline Early leaf number & 2 & 10.4 & 11.8 & 0.0001 \\
\hline Early leaf length & 2 & 58.3 & 17.13 & 0.0001 \\
\hline Mid leaf number & 3 & 936.17 & 32.47 & 0.0001 \\
\hline Mid leaf length & 3 & 78.54 & 23.45 & 0.0001 \\
\hline CH flowers & 2 & 11.7 & 6.29 & 0.0025 \\
\hline Early CL flowers & 2 & 18.4 & 4.78 & 0.0101 \\
\hline Total CL flowers & 3 & 27.5 & 2.87 & 0.0385 \\
\hline CH fruit & 2 & 13.8 & 8.54 & 0.0003 \\
\hline CL fruit & 2 & 17.94 & 6.95 & 0.0014 \\
\hline
\end{tabular}

Differences in mating system expression among populations were also observed for fruit production. For $\mathrm{CH}$ fruit production, plants at PP produced more fruit than those at $\mathrm{KM}$, and KM plants produced more fruit than OS (Fig. 2B). Thus, although KM and PP produced equal numbers of $\mathrm{CH}$ flowers, plants at PP were more successful than those at KM in converting flowers to fruits. Cleistogamous fruit production differed significantly among sites, with KM producing non-significantly more fruit than PP, and PP producing more than OS. Thus, the early season advantage of plants at KM in producing CL flowers does not translate into increased CL fruit production. In sum, the populations differ in the relative rates of reproduction through $\mathrm{CH}$ vs. CL fruits. Individuals within $\mathrm{KM}$ reproduce more through $\mathrm{CL}$ than $\mathrm{CH}$ fruit production, whereas individuals within PP are equally likely to produce $\mathrm{CH}$ and $\mathrm{CL}$ fruits. Individuals in $\mathrm{OS}$ have low 


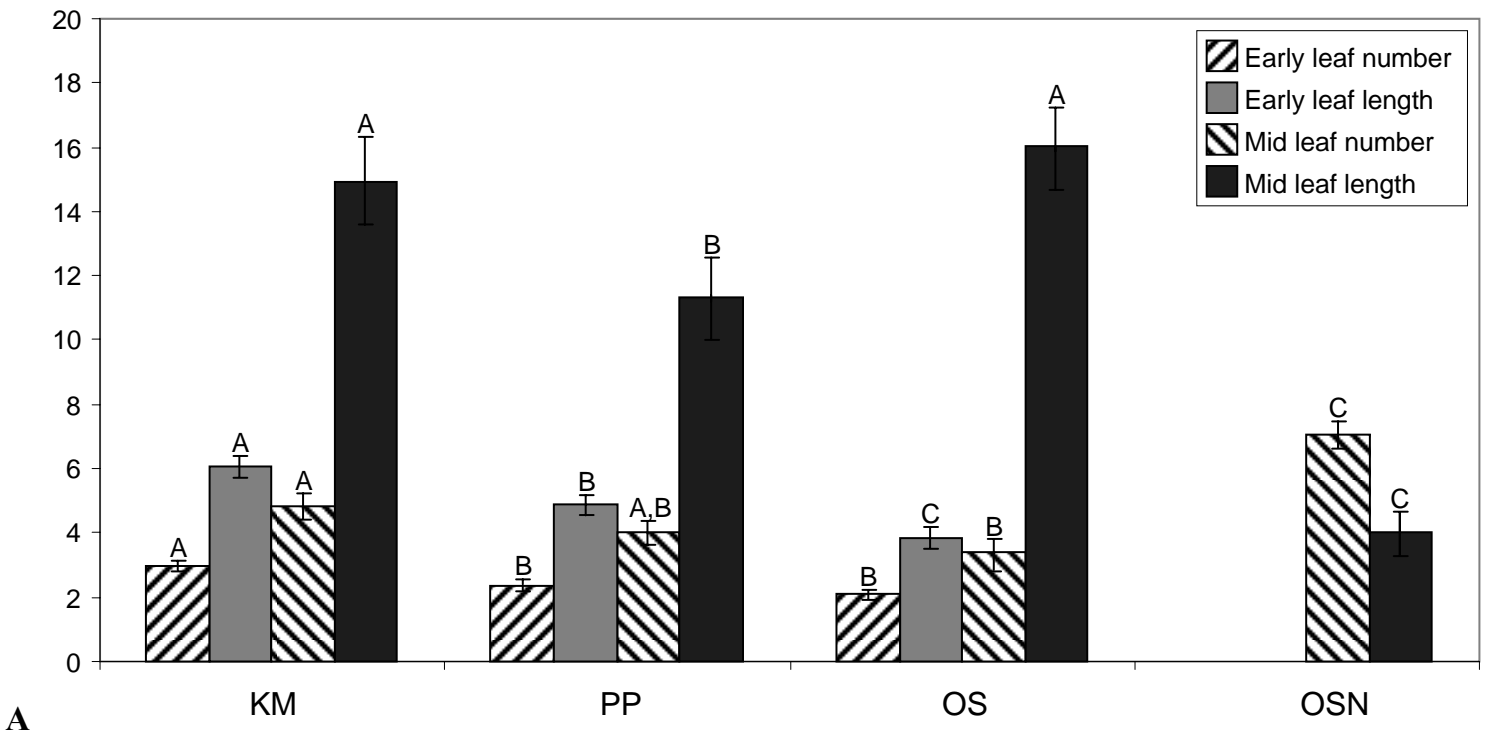

$\mathbf{A}$

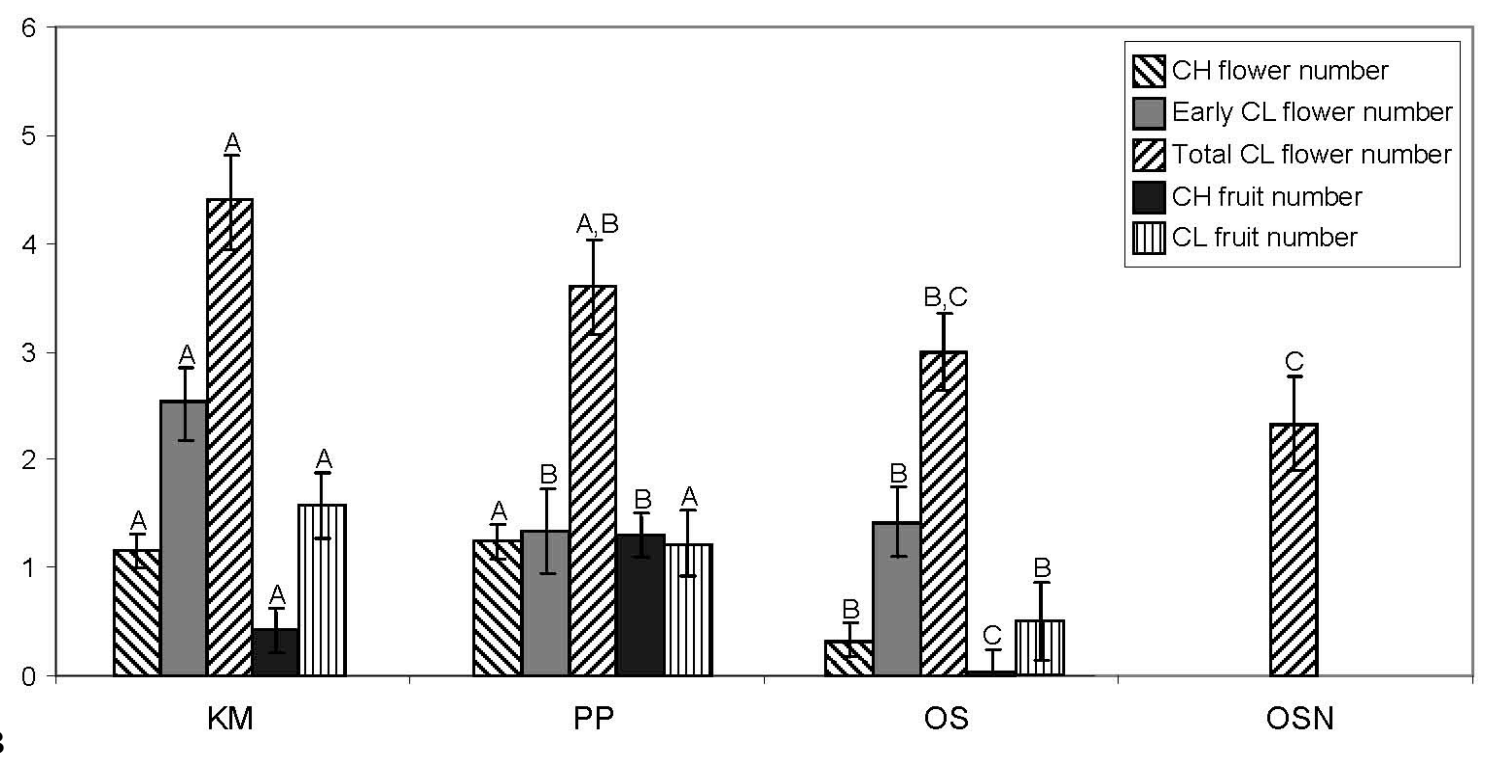

Fig. (2). Population differences in the expression of $\mathbf{A}$ ) leaf traits and $\mathbf{B}$ ) reproductive traits. Population means \pm 1 SE are shown.

reproduction overall, but cleistogamy accounts for the little reproduction that occurs (cf $\mathrm{CH}$ vs. CL fruit numbers, Fig. 2B).

The differences described in the preceding paragraph in flower and fruit production among populations may be due to differences in the frequency of reproductive individuals or in the mean number of flowers produced by reproductive individuals. Chi-square tests indicate that populations differed significantly in the frequency of individuals that produced $\mathrm{CH}$ and $\mathrm{CL}$ flowers as well as $\mathrm{CH}$ and $\mathrm{CL}$ fruits (Table 3). Nearly half of the individuals in KM and PP were reproductive and produced $\mathrm{CH}$ flowers, while only $18 \%$ of the individuals at $\mathrm{OS}$ produced $\mathrm{CH}$ flowers (Table 4). Pioneer Park had a higher frequency of individuals producing $\mathrm{CH}$ fruit than $\mathrm{KM}$, and individuals at $\mathrm{KM}$ produced $\mathrm{CH}$ fruit at a higher rate than those at OS. Thus, although an equal frequency of individuals at KM and PP initiate $\mathrm{CH}$ flowers, population differences described above for average $\mathrm{CH}$ fruit production (Fig. 2B) arise from differences in the frequency with which reproductive individuals convert flowers to fruit. The population consisting entirely of new germinants (OSN) and KM had the highest frequency of individuals producing CL flowers, followed by OS and PP. Kane Meadows and PP had roughly equal numbers of individuals producing CL fruit, and this was again higher than the frequency at OS (Table 4). Thus, the frequency with which populations both initiate flowers and convert flowers to fruit affects total CL fruit production (Fig. 2B).

Table 3. Chi-Square Test for Population Differences in the Frequency of Reproductive Individuals

\begin{tabular}{|c|c|c|c|c|}
\hline Trait & & df & $\chi^{2-\text { value }}$ & P-value \\
\hline \hline \multirow{2}{*}{ Flowers } & $\mathrm{CH}$ & 2 & 11.44 & 0.0033 \\
\cline { 2 - 5 } & $\mathrm{CL}$ & 2 & 6.39 & 0.0410 \\
\hline \multirow{2}{*}{ Fruits } & $\mathrm{CH}$ & 2 & 14.44 & 0.0007 \\
\cline { 2 - 5 } & $\mathrm{CL}$ & 2 & 10.90 & 0.0043 \\
\hline
\end{tabular}


Table 4. Frequency of Reproductive Individuals Observed within each Population

\begin{tabular}{|c|c|c|c|c|}
\hline \multirow{2}{*}{ Population } & \multicolumn{2}{|c|}{ Flowers } & \multicolumn{2}{c|}{ Fruit } \\
\cline { 2 - 5 } & CH & CL & CH & CL \\
\hline \hline KM & 48.8 & 75.6 & 22.2 & 55.5 \\
\hline PP & 45 & 46.2 & 38.5 & 47.8 \\
\hline OS & 18 & 60 & 4 & 22.9 \\
\hline OSN & 0 & 77 & 0 & NA \\
\hline
\end{tabular}

With regard to the mean number of flowers produced by individuals that reproduced, the pattern was for plants at KM and PP to have 1 more $\mathrm{CH}$ flower on average than those at OS, and plants at KM typically had 1 more CL flower early in the season than plants at either PP or OS (data not shown). However, these differences in mean $\mathrm{CH}$ and $\mathrm{CL}$ flower production among populations were non-significant $(\mathrm{P}>$ 0.40 for population effect for both traits). Differences in fruit set were impossible to evaluate statistically due to the small number of individuals within OS that produced fruit (see Fig. 2B).

To test for potential tradeoffs, we examined correlations among reproductive modes. The average correlation between $\mathrm{CH}$ and $\mathrm{CL}$ flower production over all populations was positive $\left(\beta=0.16, p=0.001\right.$, model $\left.r^{2}=0.23\right)$. Logistic regression of stolon presence (or absence) on reproductive characters showed a significantly negative correlation between stolons and the number of CL flowers (Table 5A), where the regression estimate indicates that for every unit increase in flower number, there was a 0.69 decrease in stolon production. This result indicates a tradeoff in asexual $v s$. sexual reproduction.

Table 5. Logistic Regression Testing A) the Relationship between Stolon Production and Total $\mathrm{CH}$ and $\mathrm{CL}$ Flower Production and B) the Relationship between Stolon Production and Plant Size

A)
\begin{tabular}{|c|c|c|c|c|c|}
\hline & Df & Estimate & $\begin{array}{c}\text { Standard } \\
\text { error }\end{array}$ & Wald $\chi^{2}$ & $\mathbf{P}>\chi^{2}$ \\
\hline \hline Intercept & 1 & 0.16 & 0.57 & 0.08 & 0.77 \\
\hline $\begin{array}{c}\text { CH flower } \\
\text { number }\end{array}$ & 1 & -7.42 & 95.17 & 0.01 & 0.94 \\
\hline $\begin{array}{c}\text { CL flower } \\
\text { number }\end{array}$ & 1 & -0.69 & 0.31 & 4.99 & 0.03 \\
\hline
\end{tabular}

B)

\begin{tabular}{|c|c|c|c|c|c|}
\hline & Df & Estimate & Standard error & Wald $\chi^{2}$ & $\mathbf{P}>\boldsymbol{\chi}^{2}$ \\
\hline \hline Intercept & 1 & 5.14 & 2.35 & 4.77 & 0.03 \\
\hline Leaf number & 1 & -1.87 & 0.86 & 4.68 & 0.03 \\
\hline Leaf length & 1 & -0.82 & 0.39 & 4.53 & 0.03 \\
\hline
\end{tabular}

We used ANCOVA to evaluate the association between mating system expression and both plant size and microsite variation in abiotic factors. The overall model for each of the 5 analyzed traits was significant at $\mathrm{P}<0.0003$, and therefore remained significant following a sequential Bonferroni correction for multiple tests. Plant size (estimated as leaf number and leaf length early in the season) was significantly associated with variation in $\mathrm{CH}$ flower and fruit production (Table 6). More specifically, ANCOVA indicate that size variation accounts entirely for population differences in $\mathrm{CH}$ flower and fruit production, that is, the effect of population on $\mathrm{CH}$ flower and fruit production becomes non-significant once size is statistically controlled (cf. Tables 2 vs. 6). We used regression analyses (PROC GLM, SAS 2004) to determine the direction of significant associations between plant size and number of $\mathrm{CH}$ flower and fruit, i.e., $\mathrm{CH}$ flower and fruit production were regressed separately on leaf length and leaf number. Leaf length was positively associated with $\mathrm{CH}$ flower production $(\beta=2.46)$, while leaf number was positively correlated with both $\mathrm{CH}$ flower $(\beta=0.83)$ and fruit $(\beta=0.62)$ production. No measured abiotic factors contributed to variation in $\mathrm{CH}$ flower or fruit production (Table 6).

ANCOVA indicate that variation in plant size as well as moisture and light conditions were associated with earlyseason CL flower production, total CL flower production, and $\mathrm{CL}$ fruit production (Table 6). As with $\mathrm{CH}$ flower and fruit production, numbers of CL flowers and fruits increased with increasing leaf length and leaf number (data not shown). Interestingly, the 2-way interactions of moisture $\times$ population, light $\times$ population, and moisture $\times$ light were all significant or marginally so for early CL flower production, total CL flower production, and CL fruit production (Table 6). Graphical inspection of the data suggests that the significant moisture $\times$ population and light $\times$ population interactions derive from similar response patterns for all 3 traits. Using total CL flower production as an example, the significant moisture $\times$ population interaction effect apparently derives from the fact that the relationship between moisture and $\mathrm{CL}$ reproduction reverses across populations (Fig. 3A); in KM (the driest population on average over all microsites) CL flower production increases with increasing microsite moisture levels, in OS (the population with intermediate moisture) the relationship between microsite moisture and CL flower production is non-significant, in PP (the wettest population) CL flower production increases with decreasing microsite moisture levels. Using total CL flower production as an example again, the significant light $\times$ population interaction appears to derive from the fact that CL flower number generally increases as light intensity decreases, but to differing degrees among populations (Fig. 3B). The significant moisture $\times$ light interaction derives simply from accelerating CL flower production with high moisture in combination with low light within the KM population; no well-supported secondary peaks indicative of other favorable moisture $\times$ light combinations are observed in three-dimensional plots of the data (data not shown).

Plant size was also associated with variation in asexual reproduction. In particular, larger plants had lower stolon production (Table 5B). A priori, the expectation might have been that large plants would both increase CL flower number, as described in the preceding Results, and stolon production, but this is not the case. Neither soil moisture, 
Table 6. Analysis of Covariance Testing the Effects of Plant Size and Abiotic Factors on Reproductive Output. Model $\mathbf{r}^{2}$ range from 0.29-0.46

\begin{tabular}{|c|c|c|c|c|c|c|c|c|c|c|c|c|c|c|c|c|c|c|c|c|}
\hline \multirow{3}{*}{$\begin{array}{l}\text { Source of } \\
\text { variation }\end{array}$} & \multicolumn{12}{|c|}{ Flowers } & \multicolumn{8}{|c|}{ Fruit } \\
\hline & \multicolumn{4}{|c|}{$\mathbf{C H}$} & \multicolumn{4}{|c|}{ Early CL } & \multicolumn{4}{|c|}{ Total CL } & \multicolumn{4}{|c|}{ CH } & \multicolumn{4}{|c|}{ CL } \\
\hline & df & MS & $\mathbf{F}$ & Pr $>$ F & df & MS & $\mathbf{F}$ & $\operatorname{Pr}>\mathbf{F}$ & Df & MS & $\mathbf{F}$ & $\mathbf{P r}>\mathbf{F}$ & df & MS & $\mathbf{F}$ & $\operatorname{Pr}>\mathbf{F}$ & df & MS & $\mathbf{F}$ & $\operatorname{Pr}>\mathbf{F}$ \\
\hline Population & 2 & 0.08 & 0.06 & 0.945 & 2 & 11.17 & 4.31 & 0.016 & 2 & 59.96 & 8.24 & 0.001 & 2 & 0.02 & 0.02 & 0.982 & 2 & 11.20 & 6.37 & 0.003 \\
\hline Early leaf length & 1 & 12.22 & 8.72 & 0.003 & 1 & 33.88 & 13.08 & 0.001 & 1 & 62.18 & 8.54 & 0.004 & 1 & 2.42 & 1.69 & 0.196 & 1 & 10.77 & 6.13 & 0.015 \\
\hline Early leaf number & 1 & 6.29 & 4.49 & 0.036 & 1 & 23.69 & 9.15 & 0.003 & 1 & 42.18 & 5.79 & 0.018 & 1 & 5.95 & 4.16 & 0.043 & 1 & 13.09 & 7.45 & 0.008 \\
\hline Moisture & 1 & 0.71 & 0.51 & 0.476 & 1 & 6.12 & 2.37 & 0.127 & 1 & 17.44 & 2.40 & 0.125 & 1 & 0.20 & 0.14 & 0.712 & 1 & 1.37 & 0.78 & 0.380 \\
\hline Light & 1 & 0.30 & 0.21 & 0.645 & 1 & 18.83 & 7.27 & 0.008 & 1 & 81.85 & 11.24 & 0.001 & 1 & 0.06 & 0.04 & 0.844 & 1 & 9.95 & 5.66 & 0.019 \\
\hline Moisture $\times$ population & 2 & 0.21 & 0.08 & 0.926 & 2 & 8.59 & 3.32 & 0.040 & 2 & 53.16 & 7.30 & 0.001 & 2 & 0.07 & 0.05 & 0.952 & 2 & 12.06 & 6.86 & 0.002 \\
\hline Light $\times$ population & 2 & 0.73 & 0.26 & 0.771 & 2 & 5.97 & 2.31 & 0.105 & 2 & 22.47 & 3.09 & 0.050 & 2 & 0.33 & 0.23 & 0.791 & 2 & 4.28 & 2.44 & 0.093 \\
\hline Moisture $\times$ light & 1 & 0.80 & 0.57 & 0.450 & 1 & 11.90 & 4.60 & 0.035 & 1 & 38.55 & 5.29 & 0.024 & 1 & 0.27 & 0.19 & 0.667 & 1 & 5.38 & 3.06 & 0.083 \\
\hline
\end{tabular}

irradiance, nor temperature were significantly associated with stolon production (data not shown).

\section{DISCUSSION}

Mating system expression varied among populations as well as among microsites in the locally threatened species, $V$. lanceolata. Plants within the oldest two populations (Kane Meadows and Pioneer Park) produced more $\mathrm{CH}$ flowers than those within the two youngest populations (Open Space and Open Space New) (Fig. 2B). However, plants within PP produced more $\mathrm{CH}$ fruit than both $\mathrm{KM}$ and $\mathrm{OS}$ populations. An analogous pattern of variable total CL flower production and fruit maturation was observed among the KM, PP, OS, and OSN populations. These population differences in reproductive output arose in part from variation in the frequency of reproductive individuals (i.e., the frequency of individuals producing at least one flower) and in part from differential success in fruit maturation (i.e., the frequency of individuals converting at least one flower to a fruit); the role of mean flower/fruit production by reproductive individuals was unclear. Mechanistically, population differences may be explained by variation in plant size; plants at PP and KM were larger early in the season (Fig. 2A) and potentially better able to support production of, for instance, costly $\mathrm{CH}$ flowers and eventual $\mathrm{CH}$ fruit maturation than smaller plants at OS (see also Solbrig 1981). Pollen-limitation might have reduced fruit set of $\mathrm{KM}$ relative to $\mathrm{PP}$ plants. The KM population had $<50 \mathrm{CH}$ flowering plants, while PP had $>700$ $\mathrm{CH}$-producing individuals. Viola lanceolata's potential pollinators are in the genera Osmia and Andrena and members of the Halictidae (Beattie 1974), which have small foraging ranges (Beattie and Culver 1979) and may not be attracted to small plant populations (Beattie 1976). Although the small sample size makes it difficult to generalize to disturbance history, observed differences in the likelihood of producing flowers and maturing fruits indicate that populations apparently differ in quality.

The differences described above in the average reproductive behavior of individual plants within each population may translate into population genetic differences. At KM, about one third of both $\mathrm{CH}$ and CL flowers matured to fruit. The plants at KM, however, had higher cleistogamous than chasmogamous fruit production because more CL flowers were initiated, and thus more progeny arose from selfing than outcrossing. Within $\mathrm{PP}, \mathrm{CH}$ fruits were more likely to mature than CL fruit (100\% vs. 33\%), but similar numbers of $\mathrm{CH}$ and $\mathrm{CL}$ fruit were ultimately set because plants produced roughly one third as many $\mathrm{CH}$ as $\mathrm{CL}$ flowers. Thus, approximately equal numbers of progeny within the PP population may arise from self-fertilization $v s$. outcrossing. Within OS, virtually all progeny arose from cleistogamous fruit and thus selfing. From mating system expression alone, one might expect the least heterozygosity at the KM and OS populations, because progeny arise more from selfing than outcrossing. At KM, the small population size also means that stochastic loss of rare alleles is more likely. However, the typically erosive effect of selfing on heterozygosity and of stochastic processes on genetic variation may be mitigated in this species by the durable seed bank; wetland Viola spp. seed banks may persist for years in peat soils and germinate following disturbance (Jensen and Mayer 2001, Milburn and Husveth 2004), suggesting that all outcrossed seeds matured in the past few years (at KM) are likely contributing to diversity in the seed bank and that a new cohort of germinating individuals may be quite variable. Hypotheses on genetic diversity, however, ignore a) potential inbreeding in $\mathrm{CH}$ flowers (which we believe to be low given the apparent absence of active delayed selfing mechanisms in this species, but which could theoretically increase the frequency of selfed progeny at PP) and b) potential differences in performance at different life stages, including how many $\mathrm{CH}$ relative to $\mathrm{CL}$ seeds survive to reproduce and what the relative fecundity is of both $\mathrm{CH}$ and $\mathrm{CL}$ progeny as well as asexual progeny. The few existing studies provide variable evidence that seed size (Elisafenko 2001, Culley 2002, Eckstein and Otte 2005) and germination (BülowOlsen 1984, Berg and Redbo-Torstensson 1999, Elisafenko 2001, Culley 2002, Eckstein and Otte 2005) differ between selfed vs. outcrossed progeny in other Viola spp.

Given observed population differences in the average number of flowers produced and success at maturing fruits, demography and population growth could depend to varying degrees on $\mathrm{CH}$ vs. CL reproduction among populations. As described above, plants at KM produced more CL than $\mathrm{CH}$ fruits, and likely produced more $\mathrm{CL}$ than $\mathrm{CH}$ seeds. This 

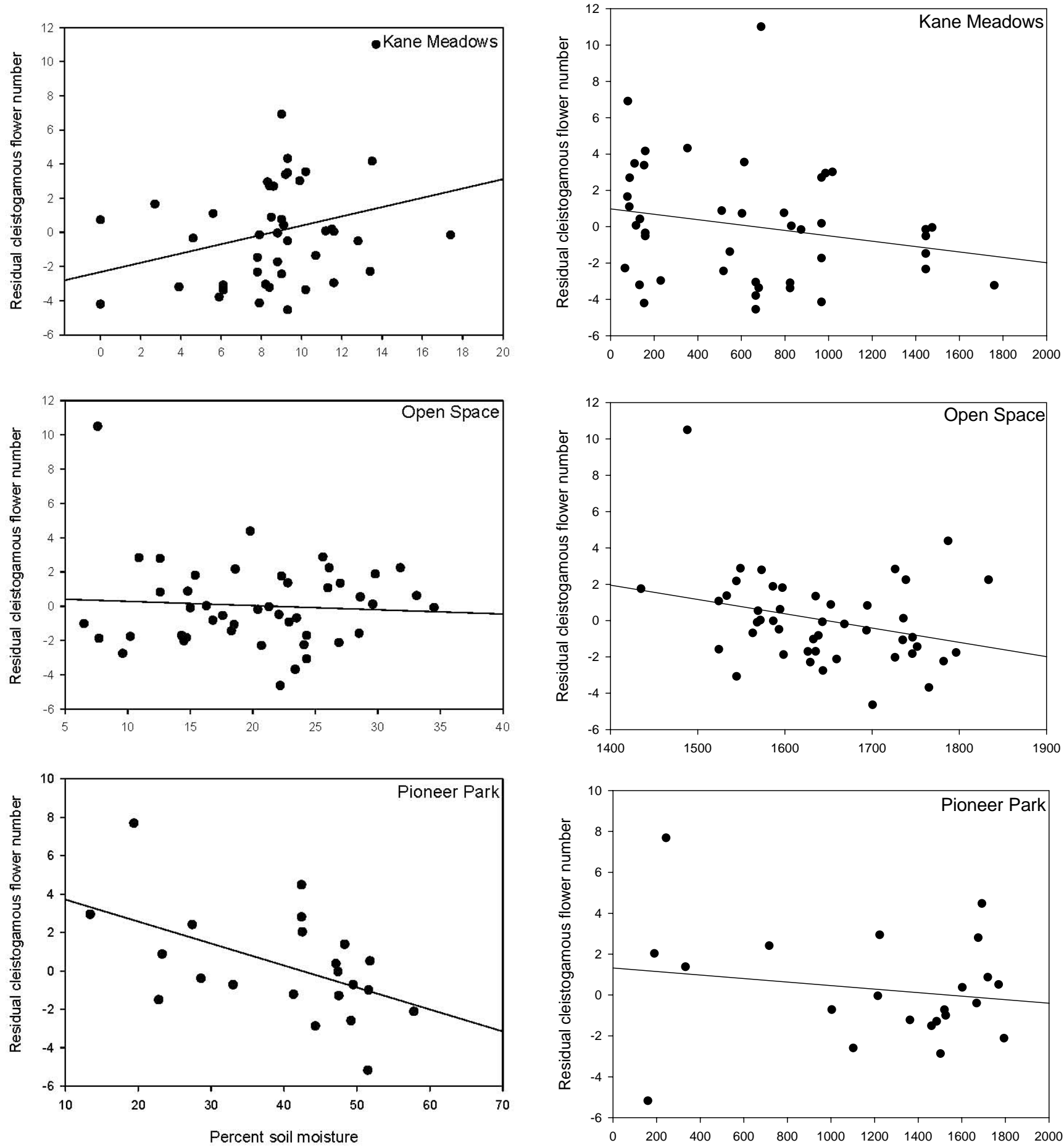

A

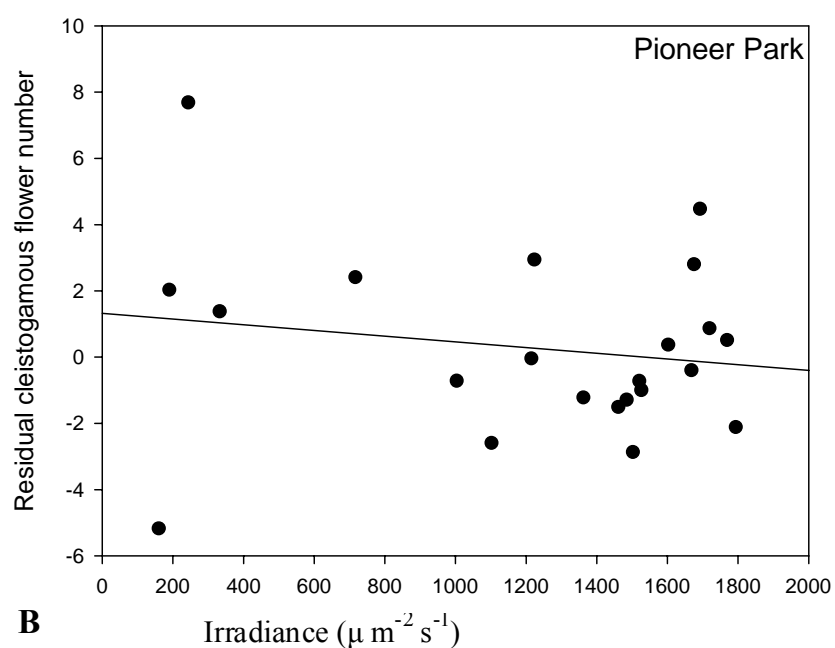

Fig. (3). Relationship between A) moisture and residual CL flower production by population (after effects of leaf number and leaf size are statistically controlled) and B) irradiance and residual CL flower production by population.

suggests that population growth/persistence at KM depends more on cleistogamous than chasmogamous reproduction. At $\mathrm{PP}$, approximately equal numbers of $\mathrm{CH}$ and $\mathrm{CL}$ fruit were matured, suggesting that both reproductive modes are important to population growth. At OS, almost exclusively CL fruit were matured, suggesting that population demography at this population (and perhaps young populations in general) relies on self-fertilized seeds. It is perhaps worth noting that observed population differences in mating system expression may arise from plasticity to abiotic factors that differ across the 4 study sites or from genetic differentiation for canalized trait expression; nevertheless, regardless of the mechanism underlying differential $\mathrm{CL}$ vs. $\mathrm{CH}$ reproduction, potential effects of mating system on population genetics and demographic patterns exist. Additional studies on performance across life-history stages would be beneficial, but the results 
presented in this study on floral initiation rate and fruit maturation success nevertheless generate testable hypotheses regarding the possible importance of mating system and population disturbance history to demography and population genetics.

In addition to variation among populations, microsite variation in abiotic factors was also associated with mating system expression. Production of chasmogamous flowers and fruits was generally unrelated to soil moisture levels, irradiance, and temperature, although chasmogamous reproduction was positively correlated with plant size. By contrast, the production of cleistogamous flowers and fruit was closely tied to soil moisture levels and irradiance to a lesser extent. Interestingly, the species appears to tolerate a wide range of percent soil moisture, given the range of soil moistures across the three populations, KM, OS, and PP (driest to wettest respectively) (Fig. 3A). Results from the two populations where the most CL fruit were set (KM and $\mathrm{PP}$ ) suggest that 8-20 percent soil moisture is optimal for CL reproduction (Fig. 3A), i.e., the most fruit are set by plants growing in this soil moisture range. The population $\times$ moisture for cleistogamy also highlights the fact that apparent environmental effects on trait expression will vary depending on the environmental range sampled. Finally, other factors being equal, reproduction through self-fertilization is likely to increase relative to outcrossing in populations with such intermediate soil moisture levels, because cleistogamous reproduction will be higher than in comparatively drier and wetter populations while chasmogamous reproduction will be unaffected.

Some reproductive traits were strongly correlated. Consistent with the positive association between plant size and both $\mathrm{CH}$ and $\mathrm{CL}$ flower production in the current study and in prior studies (Solbrig 1981), the correlation between $\mathrm{CH}$ and $\mathrm{CL}$ flower number was positive. Potentially, larger plants inhabit more favorable microsites (or are older), and this environmental covariance leads to a positive correlation. More specifically, large plants have sufficient resources and/or meristems to support both $\mathrm{CH}$ and $\mathrm{CL}$ flowers, while smaller plants produce fewer $\mathrm{CH}$ and $\mathrm{CL}$ flowers and fruits, resulting in a positive correlation. The question remains as to the genetic correlation between these two reproductive types. We further observed a negative correlation between sexual, cleistogamous reproduction and asexual, stolon production. Interestingly, although larger plants (as estimated from leaf size) have more CL flower production, they have reduced stolon production. Potentially, early allocation of meristems to $\mathrm{CL}$ flower production limits stolon production. Alternatively, there may be allocation tradeoffs to vegetative functions, i.e., increased leaf production comes at the cost of stolons, and this underlies the tradeoff with cleiostogamy; resource limitation seems less likely, however, because increases in leaf number should increase the carbon pool available for both flower and stolon production (Watson 1984). Regardless of the exact mechanism, we believe that this negative phenotypic correlation reflects the genetic one; differences in vigor and environmental covariances are unlikely to contribute, because large plants did not exhibit increased allocation to both CL and stolon production. In terms of genetic structure, it appears that plants produce variable progeny via outcrossing of chasmogamous flowers and less variable/clonal progeny via either cleistogamy or stolons. This tradeoff may also affect establishment of new populations; while stolon production may be favored as a means to colonize newly disturbed microsites in this species (V. Ranua, personal observation), no colonization of distant sites is possible. Finally, the observed correlations might also affect the stability of mixed mating strategies. A recent study indicates that correlations (conflicts) among reproductive characters could favor some intermediate level of selfing, thus evolutionarily stabilizing mixed mating (Johnston et al. 2009).

Reproductive effort is one measure of habitat quality, and despite the small number of sampled populations, some results seem potentially relevant to management of $V$. lanceolata. In our study, the most frequently disturbed population, PP, had the greatest number of individuals and a high frequency of large, reproductive individuals. Individuals in this population produced fairly even numbers of $\mathrm{CH}$ and $\mathrm{CL}$ fruit, whereas the waxing (OS, OSN) and waning populations (KM) reproduced primarily via cleistogamy. Others have also observed that cleistogamy increases as environmental quality decreases (Schemske 1978, Waller 1979, Cortés-Palomec and Ballard 2006). For V. lanceolata, a high-quality habitat - one that enables high reproduction through chasmogamy, or high total reproduction - may be a frequently disturbed habitat. High-quality habitats, and the associated $\mathrm{CH} /$ outcross seed production, should contribute to heterozygosity and progeny diversity (in a single cross). A low-quality habitat - one with primary reproduction through CL seeds, or low overall reproduction - may be populations that are infrequently disturbed or undergoing natural succession. One exception is that populations of new germinants, like OSN, likely reproduce only through CL seeds the first year; in fact, we observed that individuals at OSN produced $\mathrm{CH}$ flowers in the second growing season. In general, our observations are in line with those of Solbrig et al. (1988); they found that following a disturbance event that eliminated plant competitors, $V$. lanceolata seeds germinated and produce a large seedling population. Once these seedlings became reproductive adults, they negatively affected seed germination and recruitment of new seedlings and total population growth rate declined. However, this population of reproducing adults also replenished the seed bank. Solbrig et al. (1988) also observed that with time other plants that outcompete $V$. lanceolata will invade the disturbed population. Eventually all violet plants disappear, and the population is reduced to the seed bank until another disturbance event takes place and the process repeats itself (Solbrig et al. 1988).

\section{ABBREVIATIONS}

$$
\begin{aligned}
& \mathrm{CH}=\text { Chasmogamous } \\
& \mathrm{CL}=\text { Cleistogamous }
\end{aligned}
$$

\section{ACKNOWLEDGEMENTS}

The authors thank the City of Blaine for permitting the use of public land for this research as well as LF Delph and MT Brock for comments on the manuscript. This work was supported by NSF grants DBI-0227103 \& DBI-0605736 to CW. 


\section{REFERENCES}

Banasinska, A, \& Kuta, E (1996) Allogamy in Viola odorata. Acta Biologica Cracoviensia, 38, 41-51.

Beattie, AJ (1969) The floral biology of three species of Viola. New Phytologist, 68, 1187-1201.

Beattie, AJ (1974) Floral evolution in Viola. Annals of the Missouri Botanical Garden, 61, 781-793.

Beattie, AJ (1976) Plant dispersal, pollination, and gene flow in Viola. Oecologia, 25, 291-300.

Beattie, AJ, \& Culver, DC (1979) Neighborhood size in Viola. Evolution, 33, 1226-1229.

Berg H, \& Redbo-Torstensson, P (1999) Offspring performance in three cleistogamous Viola species. Plant Ecology, 145, 49-58.

Bülow-Olsen, A (1984) Diplochory in Viola: a possible relation between seed dispersal and soil seed bank. American Midland Naturalist, $112,251-260$

Charlesworth, D, \& Charlesworth, B (1987) Inbreeding depression and its evolutionary consequences. Annual Review of Ecology and Systematics, 18, 237-268

Cortés-Palomec, AC, \& Ballard, HE Jr (2006) Influence of annual fluctuations in environmental conditions on chasmagamous flower production in Viola striata. Journal of the Torrey Botanical Society, $133,312-320$

Culley, TM (2002) Reproductive biology and delayed selfing in Viola pubescens (Violaceae) and understory herb with chasmogamous and cleistogamous flowers. International Journal of Plant Science, $163,113-122$

Darwin, $\mathrm{CH}$ (1877). The different forms of flowers on plants of the same species, Reprint, University of Chicago Press, Chicago, Illinois, USA.

Eckstein, RL, \& Otte, A (2005) Effects of cleistogamy and pollen source on seed production and offspring performance in three endangered violets. Basic and Applied Ecology, 6, 339-350.

Elisafenko, TV (2001) Morphology and biology of rare Siberian Viola. L. species seeds. Rastilel'Nya Resursy, 37, 40-46. [In Russian]

Falconer, DS \& Mackay, TFC (1996) Introduction to Quantitative Genetics. Ed 4. Longmans Green, Harlow, Essex, UK.

Geber, M (1990) The cost of meristem limitation in Polygonum arenastrum : Negative genetic correlations between fecundity and growth. Evolution, 44, 799-819.

Goodwillie, C, Kalisz, K, \& Eckert, CG (2005) The evolutionary enigma of mixed mating systems in plants: occurrence, theoretical explanations, and empirical evidence. Annual Review of Ecology, Evolution, and Systematics, 36, 47-49.

Hutchinson, MJ, \& Bradley, IK (1986) Ecological perspectives on clonal perennial herbs, when does it pay for individual clone modules to be functionally integrated or independent. BioScience, 36, 178-182.

Huber, H, Lukács, \& Watson, MA (1999) Spatial structure of stoloniferous herbs: an interplay between structural blue-print, ontogeny and phenotypic plasticity. Plant Ecology, 141, 107-115.

Jensen, K, \& Meyer, C (2001) Effects of light competition and litter on the performance of Viola palustris and on species composition and diversity in an abandoned fen meadow. Plant Ecology, 155, 169188

Keddy, PA, \& Reznicek, AA (1982) The role of seed banks in the persistence of Ontario's coastal plain flora. American Journal of Botany, 69, 13-22.

LeCorff, J, \& Horvitz, CC (2005) The contrasting roles of chasmogamous and cleistogamous reproduction in population growth and population spread in an ant-dispersed neotropical herb, Calathea micans (Marantaceae). Ecological Modeling, 188, 41-51.

Lord, EM (1981) Cleistogamy: a tool for the study of floral morphogenesis, function, and evolution. The Botanical Review, 47, 421-449.

Marcussen, T (2003) Evolution, phylogeography, and taxonomy within the Viola alba complex (Violaceae). Plant Systematics and Evolution, 237, 51-74.

Mattila, T, \& Salonen, V (1995) Reproduction of Viola mirabilis in relation to light and nutrient availability. Canadian Journal of Botany, 73, 1917-1924.

Milburn, SA, \& Husveth, JJ (2004) Conservation assessment for lanceleaved violet (Viola lanceolata L. var. lanceolata). Report for the
USDA Forest Service, Eastern Region, Milwaukee, Wisconsin, USA.

Minnesota Department of Nautural Resources (2007) Minnesota's List of Endangered, Threatened, and Special Concern Species. [Internet]. Minnesota Department of Natural Resources, Saint Paul, Minnesota, USA; cited 12 May 2009. Available from http:/files.dnr.state.mn.us/natural_resources/ets/endlist.pdf.

Mohlenbrock, RH (1978) The illustrated flora of Illinois: Flowering plants, hollies to loasas. South Illinois University Press, Carbondale, USA.

Newell, SJ (1982) Translocation of C14-photoassimilate in two stoloniferous Viola species. Bulletin of the Torrey Botanical Club, 109, 306-317.

Owen-Koning, C (2005) Vegetation patterns resulting from spatial and temporal variability in hydrology, soils, and trampling in an isolated basin marsh, New Hampshire, USA. Journal of Ecology, $25,239-251$.

Rice, WR (1989) Analyzing tables of statistical tests. Evolution, 43, 223 225.

Russell, NH (1955) The taxonomy of the North American acaulescent white violets. American Midland Naturalist, 54, 481-494.

Russell, NH (1958) The violets of Minnesota, Reprint of the Proceedings of the Minnesota Academy of Science, Minnesota Academy of Science, Saint Paul, USA, Volume 25 \& 26.

Russell, NH (1960) Studies in the photoperiodic responses of violets (Viola). Southwestern Naturalist, 5, 177-186.

Rutherford, A (2001) Introducing ANOVA and ANCOVA, a GLM approach. Sage Publications Ltd. London, UK.

Schellner, RA, Newell, SJ, \& Solbrig, OJ (1982) Studies on the population biology of the genus Viola, IV. spatial patterns of ramets and seedlings in three stoloniferous species. Journal of Ecology, 70, 273-290.

Schemske, DW (1978) Evolution of reproductive characteristics in Impatiens (Balsaminanceae): The significance of cleistogamy and chasmogamy. Ecology, 59, 596-613.

Schmitt, J, Eccleston, J, \& Ehrhardt, DW (1987) Density-dependent flowering phenology, outcrossing, and reproduction in I. capensis Oecologia, 72, 341-347.

Sokal, RR, \& Rohlf, FJ (1995) Biometry: the principles and practice of statistics in biological research, 3rd ed. Macmillan, New York, USA

Solbrig, OT (1981) Studies on the population biolgy of the genus Viola. II. the effect of plant size on fitness in Viola sororia. Evolution, 35, 1080-1093.

Solbrig, OT, Curtis, WF, Kincaid, DT, \& Newell, SJ (1988) Studies on the population biology of the genus Viola. VI. Demography of V. fimbriatula and V. lanceolata. Journal of Ecology, 76, 301-319.

Stearns, SC (1992) The evolution of life histories, Oxford University Press, New York, USA.

Steets, JA, \& Ashman, TL (2004) Herbivory alters the expression of a mixed mating system. American Journal of Botany, 91, 1046-1051.

Steets, JA, Salla, R, \& Ashmann, TL (2006) Herbivory and competition interact to affect reproductive traits and mating system expression in Impatiens capensis. American Naturalist, 167, 592-599.

Steets, JA, Wolf, DE, Auld, JR, \& Ashman, TL (2007) The role of natural enemies in the expression and evolution of mixed mating in hermaphroditic plants and animals. Evolution, 61, 2043-2055.

Swink, FA (1952) A phenological study of the flora of the Chicago region. American Midland Naturalist, 48,758-768.

Thompson, DA, \& Beattie, AJ (1981) Density-mediated seed and stolon production in Viola (Violaceae). American Journal of Botany, 68, 383-388

USDA Natural Resource Conservation Service (2006) Web Soil Survey. [Internet] USDA Soil Survey Division, Washington, D.C. USA; cited 2007 Dec 27. Available from http://websoilsurvey.nrcs.usda.gov

Waller, DM (1979) The relative costs of selfed and outcrossed seeds in Impatiens capensis (Balsaminaceae). American Journal of Botany, 66, 313-320.

Watson, M (1984) Developmental constraints: Effect on population growth and patterns of resource allocation in a clonal plant. The American Naturalist, 123, 411-426. 
Wisheu, IC, \& Keddy, PA (1991) Seed banks of a rare wetland plant community: Distribution patterns and effects of human-induced disturbance. Journal of Vegetation Science, 2, 181-188.
Wovcha, DS, Delaney, BC, \& Nordquist, GE (1995) Minnesota's St. Croix River Valley and Anoka Sandplains: A guide to native habitats, University of Minnesota Press, Minneapolis, USA.

Received: April 09, 2010

Revised: May 24, 2010

Accepted: June 08, 2010

(C) Ranua and Weinig; Licensee Bentham Open.

This is an open access article licensed under the terms of the Creative Commons Attribution Non-Commercial License (http://creativecommons.org/licenses/by$\mathrm{nc} / 3.0 /$ ), which permits unrestricted, non-commercial use, distribution \& reproduction in any medium, provided the work is properly cited. 